\title{
التجارة الخارجية لصادرات محصول القطن في ضوء ميزان المياه الإفتراضية
}

\author{
حسام الاين محمد محمد صديق
}

قسم العلوم الاقتصادية والتعاونية الزراعية - المعهد العالي للتعاون الزراعي- شبرا الخيمة- القاهرة.

Received: Jan. 26,2017

Accepted: Feb. 7, 2017

\section{الملخص والتوصيات}

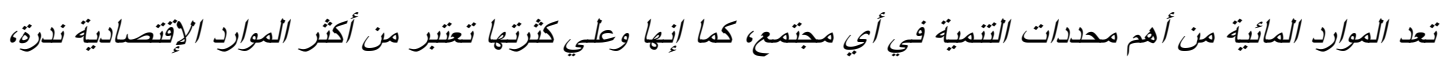

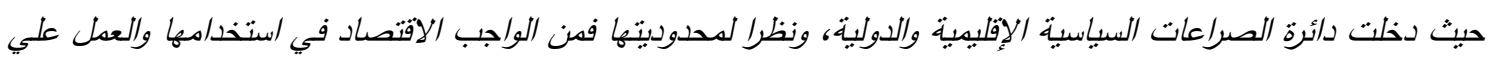
تحسين كفاءتها، خاصة الدستخدم منه في الزراعة، مع إعادة هيكلة العدلية الإنتاجية الزراعية، وإحداث تغييرات في التراكبيب الدحصولية في الزراعة الهصرية، بما بضدن الحفاظ علي هذا الدورد الهام، كما بسنلزم إعادة النظر في السياسات التصديرية، والحد من التوسع في الزراعات التصديرية عالية الاستهلاك المائي. وقد تمثلت مشكلة البحث فيما لوحظ من وجود هدر واستنزاف الموارد المائية في زراعة بعض المحاصيل الماتيل التصديرية، دون

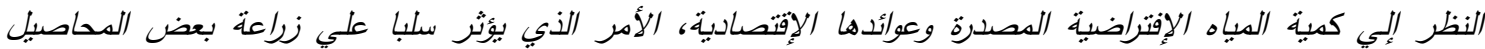
الإستراتيجية الأخري.

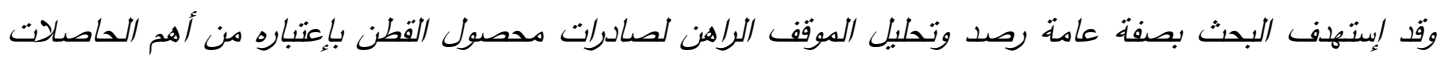
الزراعية التصديرية، وذلك بالنظر البي وضعه في ميزان العياه الإفتراضية. وقد إعتد البحث على البيانات الثانوية العنشورة

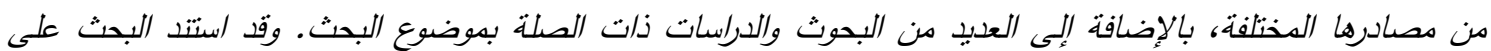

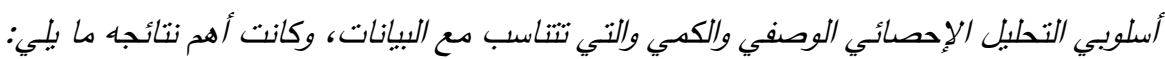
تناقص سنوي معنوي إحصائيا لمساحة القطن بلغ نحو 29.4 ألف فدان، وهذا التناقص قداني برجع البي عدم إقبال الدزارعبن

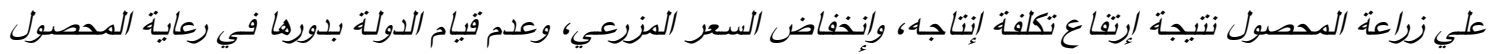

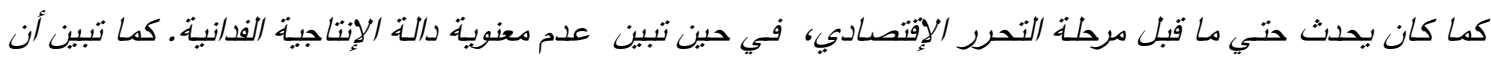
كمية الإنتاج تتتاقص سنويا بعدل معنوي إحصائيا بلغ نحو 33.8 ألف طن. كما تبين أن الصادرات الزراعية من محصول القطن تتناقص بقدار سنوي معنوي إحصائيا بلغ نحو 21.2 ألف طن.

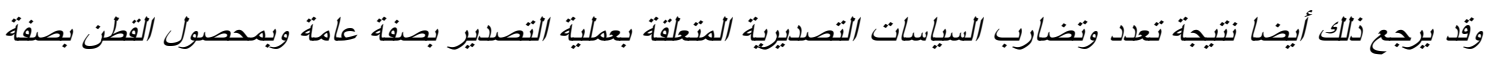

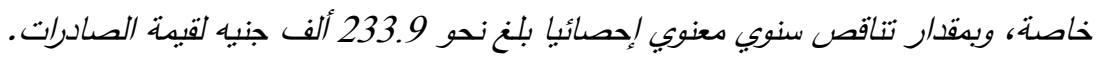
كما تبين أن هناك علاقة عكسية بين إجمالي الإنتاج الدملي من القطن و تكلفة إنتاج الفدان في السنة السابقة، حيث ينخفض إجمالي إنتاج الدحصول بنحو 0.223 ألف طن لكل زيادة قدرها جنيها واحدا في نكلفة إنتاج الفدان في السنة

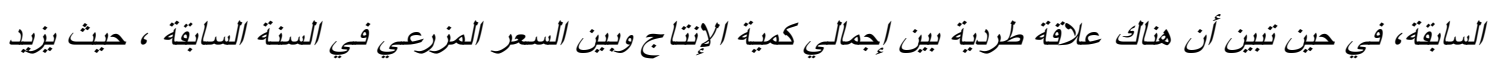

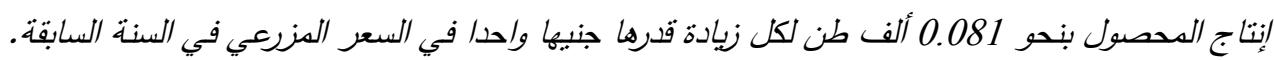

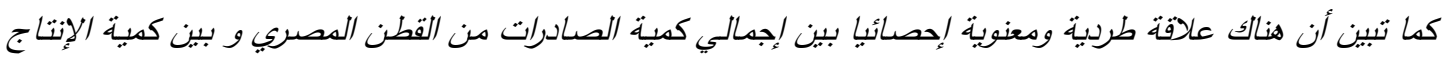
في السنة السابقة، حيث تزيد كمية الصادرات من المحصول بقدار 0.138 ألف طن لكل زيادة قدرها ألف طن من الإنتاج

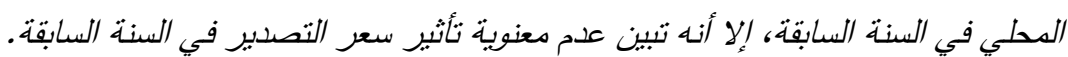

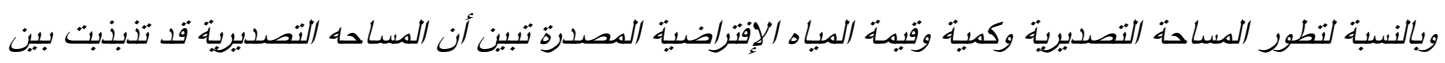

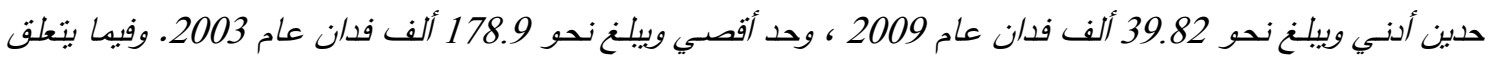




\section{Sediek}

بالمقنن الدائي للمحصول خلال تلك الفترة فقد تبين أنها بتراوح بين حدين أدنسي وبيلغ نحو 2.8 ألف م عام 2005، وحد

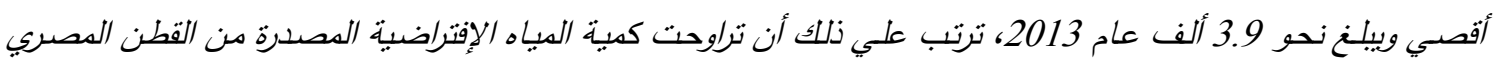

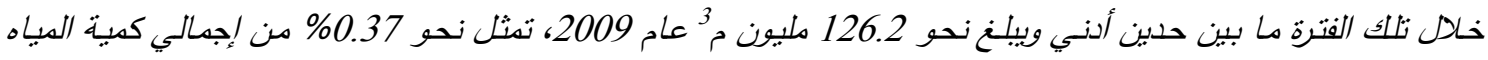
المستخدمة في الزراعة الدصرية والبالغة نحو 34.6 مليار م3 خلال نفس العام، ويقيهة مالية بلغت نحو 39.7 مليون جنيه،

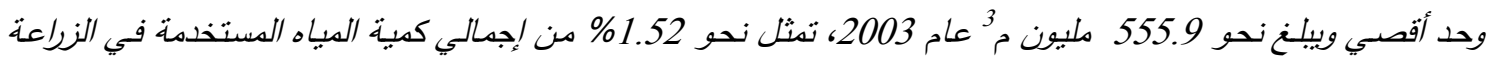
الدصرية والبالغة نحو 36.6 مليار م3 خلال نفس العام، ويقيهة مالبة بلغت نحو 175.1 ملبيون جنيه، وبتوسط كمية مياه

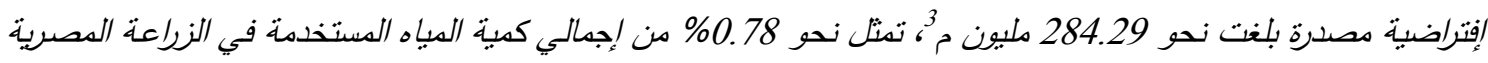
والبالغة نحو 36.4 مليار م خلال نفس الفترة.

وبالنسبة للعائد المزرعي والتصديري والدجتمعي لوحدة المباه الإفتراضية الدصدرة فقد تبين تباين العائد المزرعي لوحدة

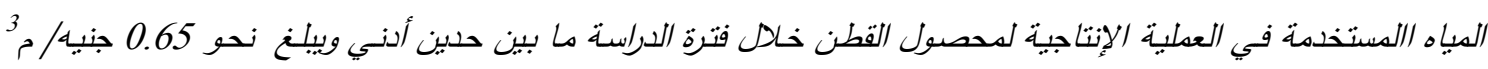

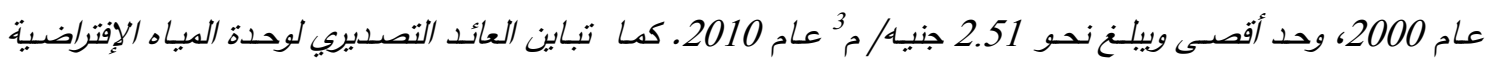

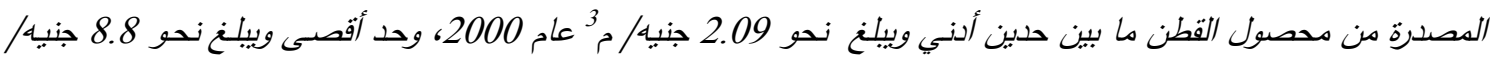

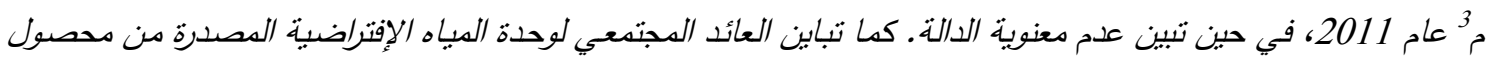

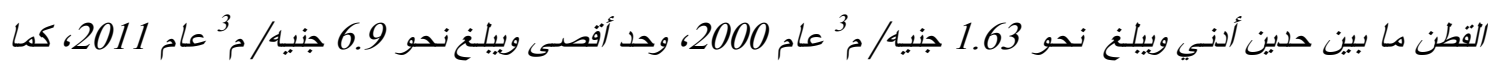
تبين عدم معنوبة الدالة.

ويالنسبة للإحتياجات والنكلفة المائية وصافي العائد فقد تبين تنبنبت قيهة النكلفة المائية الفدانية لمحصول القطن ما بين حدين أدنى ويبلغ نحو 888.9 جنيه عام 2005، وحد أقصي وبيلغ نحو 1232 جنيه عام 2013. في حبن بلنغ متوسط قيهة

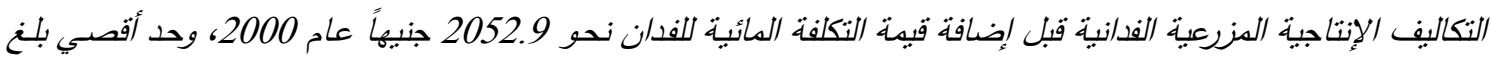
نحو 5626 جنيهاً عام 2013، كما تباينت قيهة النكاليف الإنتاجية الفدانية بعد إضافة قيهة التكلفة المائية للفدان ما بين ولين حدين أدني وبيلغ نحو 2994.5 جنيهاً عام 2002، وحد أقصي ويبلغ نحو 6858.9 جنيهاً عام 2013. بينما تنزايدت قيهة

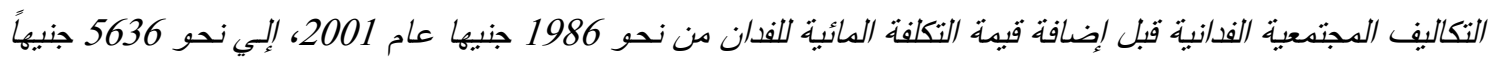

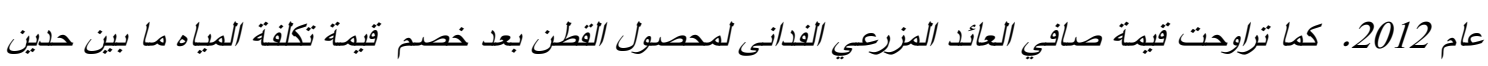

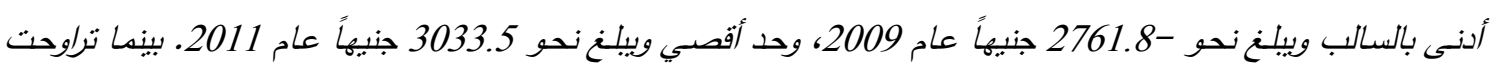

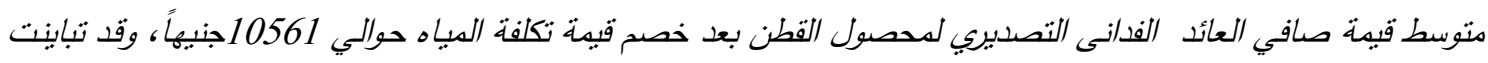

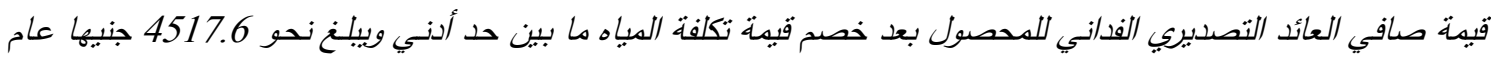

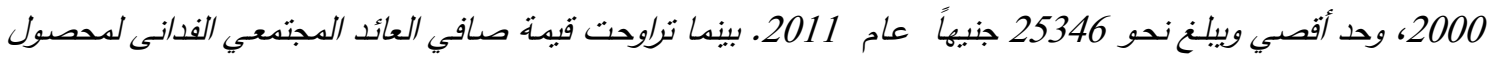
القطن بعد خصم قبهـة تكلفة المباه ما بين حدين أدنسى وبيلنغ نحو 2822.2 جنبهاً عام 2000، وحد أقصسي وبيلنغ نحو 18399 جنيهاً عام 2011. بينما تذبذبت قيمة النكلفة المائية لإجمالي المساحة التصديرية لمحصول القطن ما بين حدين أدنس وبيلنغ نحو 39.7

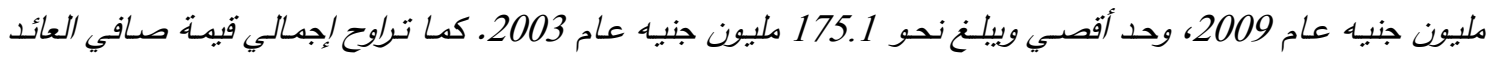

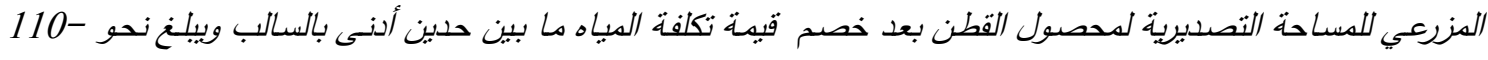

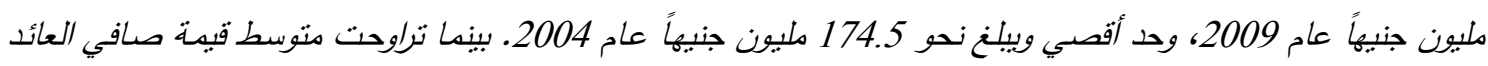
التصديري لإجمالي الدساحة التصديرية لمحصول القطن بعد خصم قبية نكلفة المباه حوالي 848.7 مليون جنيه، وقد تباينت قيهة صافي العائد التصديري للمحصول للمساحة التصديرية بعد خصم قيهة تكلفة المياه ما بين حد أدنسي ويبلن نحو 396.4

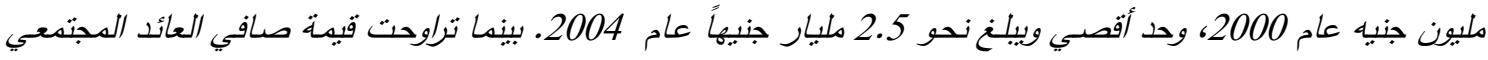




\section{Foreign trade exports cotton crop and relationship virtual water}

لإجمالي المساحة التصديرية لمحصول القطن بعد خصم قيمة تكلفة المباه ما بين حدين أدنى وبيلغ نحو 247.6 مليون جنبه عام 2000، وحد أقصي وييلغ نحو 1.8 مليار جنبه عام 2004.

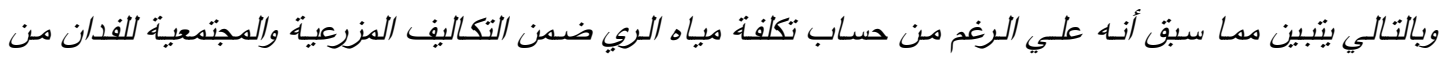
محصول القطن، إلا أنه بتحقق صـافي عائد موجب وبالرغم من إنخفاضسه علي مستوي المزارع وإتنفاعه علي المستوي الإقتصادي والدجتمي، إلا أن الأمر بشير البي مدي ربحبة تجارة المباه الإفتراضية لمحصول القطن، وبالتالي فإن البحث بري

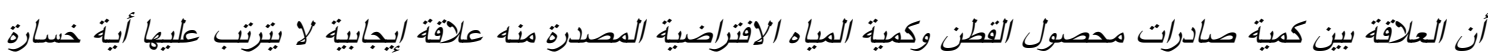
|قإقتصادية أو مجتدعية.

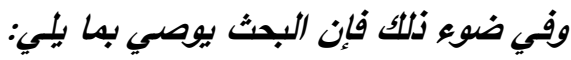
- زيادة المساحة المنزرعة من محصول القطن. - زياد السعر المزرعي الذي يحصل عليه المزارعين من محصول القطن. - زيادة الطاقة التصديرية من محصول القطن. - ضرورة إذخال قيهة الدورد الدائي ضمن حسابات التكاليف والعوائد حالة إتخاذ القرارات الإقتصادية الدتعلقة بالسياسات الإنتاجية والتصديرية لدحصول القطن وذلك في ضوء إعتبار الدورد المائي مورد إقتصادي قابل للإتجار والإنتقال داخل

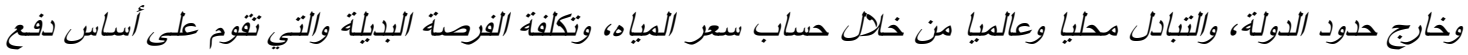
الدستلك للقيمة الحقبقية للمباه الدستهكة (حتى وإن كانت سياسات التسعبر تخضع في مضدونها للجانب النظري). الكلمات المفتاحية: التجارة الخارجية- القطن - المباه الإفتراضية.

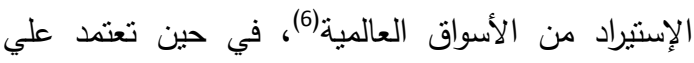

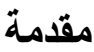

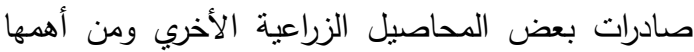
القطن وذلك لما إنتّهر به بصفاته المتميزة من حيث طول التيلة، والمتانة والنعومة والتجانس، وذلك لتوفير النقا الأجنبي (8)دون النظر لدحتواه من المياه الإفتراضية. Virtual ) ويذكر أن مفهوم المياه الإفتراضية Water (Embodied Water) (Exogenous Water)

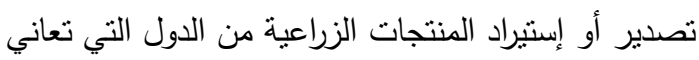
فقرا في مواردها المائية هو بمثابة تصدير أو إستيراد لمواردها المائية (تجارة بالمياه الإفتراضية)، ويمكن الإثارة إلى إمكانية استيراد المياه الإفتراضية من خلال إستيراد منتجات أو سلع إستخدمت فيها، وإمكانية تصدير المياه الإفتراضية من خلال تصدير منتجات إستخدمت نلاتك المياه في إنتاجها، وهذا الأمر يعتبر ذو حساسية كبيرة

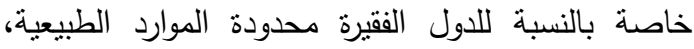
تعد الموارد المائية أحد أهم التحديات التى يواجهها

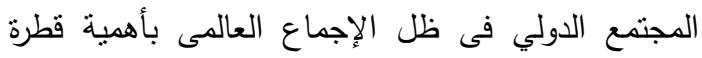

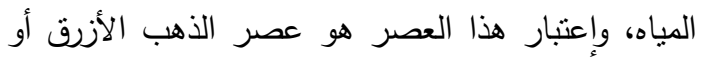

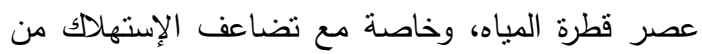
الموارد المائية، وتتامي الطلب عليها فى إطار الزيادات

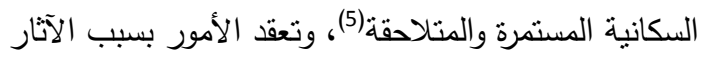
المنوقعة للتغيرات المناخية علي نتاقص موارد المياه العذبة(3)، وتصنف مصر كإحدى دول العالم دون الفقر

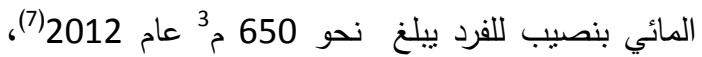
ويعتبر القطاع الزراعي هو المستهلك الرئيسي للمياه في مصر حيث يستهلاك نحو 82\% من جملة الإستهلاك

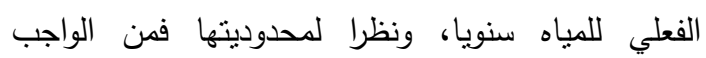
الإقتصاد في إستخدامها والعمل علي تحسين كفائتها(3)، حيث نعاني مصر من وجود فجوة غذائية كبيرة تتمنل في الفارق بين الإنتاج والإستهلالك وتزداد هذه الفجوة إنساعا

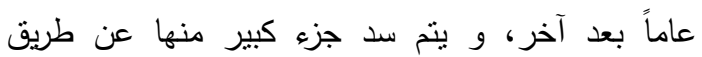


- تقدير المساحات الإفتراضية والإحتياجات والتكلفة المائية الفعلية لها، ومن ثم الوقوف علي مدي منطقية الإنية السياسة التصديرية للمحصول من الناحية الإقتصادية

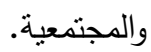

\section{مصادر البيانات والأسلوب البحثي:}

إعتمد البحث على البيانات الثانوية المنشورة من البنابل

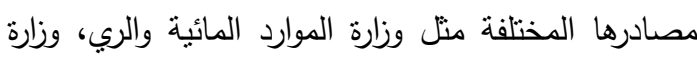

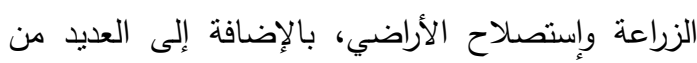

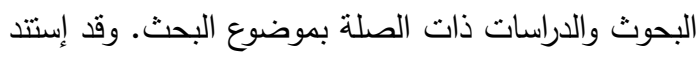
البحث على أسلوبي التحليل الإحصائي الوصفي والكمي

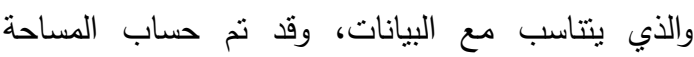
التصديرية، كمية المياه الإفتراضية المصدرة، قيمة المياه

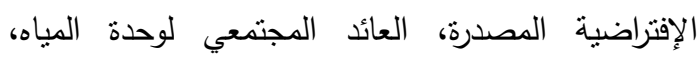
الإحتياجات المائية الكلية، التكلفة المائية الفدانية والكلية إستتادا لما يلي:

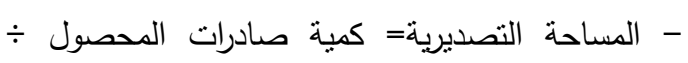
الإنتاجية الفدانية.

- كمية المياه الإفتراضية المصدرة= المساحة التصديرية × المينة

$$
\text { المقنن المائي للمحصول. }
$$

- قيمة المياه الإفتراضية المصدرة= كمية المياه الإفتراضية المصدرة × سعر المتر المكعب للمياه (31.5 قرش) (5، 6.

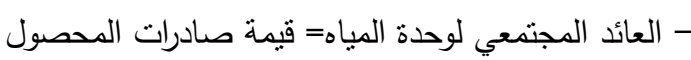

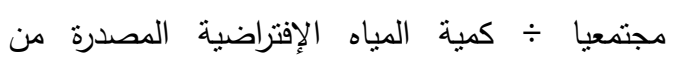

$$
\text { المحصول. }
$$

- التكلفة المائية الفدانية= المقنن المائي للمحصول × سعر المتر المكب للمياه (31.5 قرش). - التكلفة المائية الكلية للمحصول= التكلفة المائية الفدانية × المساحة الكلية المزروعة بالمحصول.

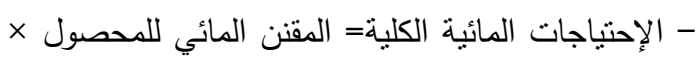

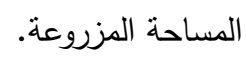

النتائج ومناقشتها: 1- المؤثرات الإنتاجية والإقتصادية
ويمكن إستخدامه فقط لتوضيح أبعاد المسألة المائية لصناع القرار، وزيادة الوعي لاى المجتمع، ومن ثم تعديل

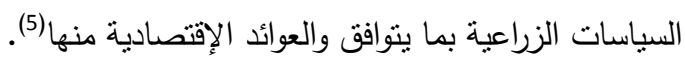

\section{مشكلة البحث: - مث:}

تعد مشكلة الفجوة المائية المستقبلية من أهم المعطيات التي تواجه الآمال المرجوة من الزراعة المصرية لتحقيق

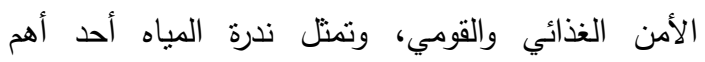

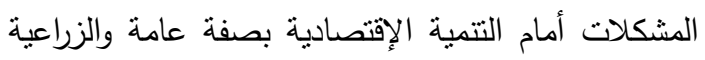
بصفة خاصة، وذلك لكونها أحد المحددات الهامة التي يتوقف عليها التوسع في مجالات التتمية، ومن ثم تدعو الحاجة إلى إتباع إستراتيجية للأمن الغذائي محورها

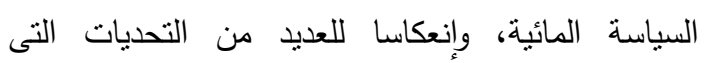
تواجهها مصر والمتمثلة فى الطلب المتتامى على الموارد المائية خاصة مع الظروف المعروفة من موجات الجفاف ومشاكل المياه عالميا وعربيا، بالإضافة إلى المشاكل

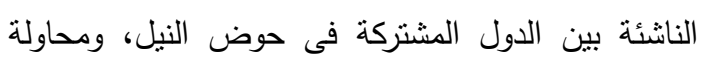

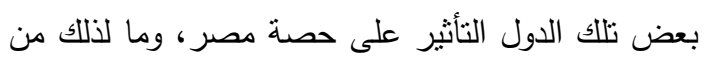

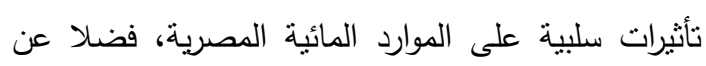

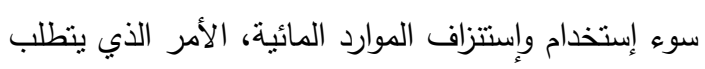

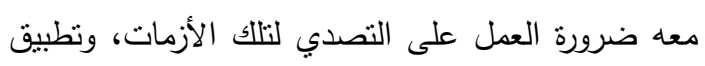

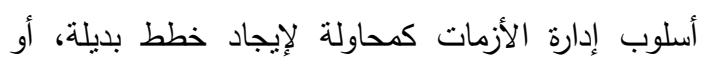

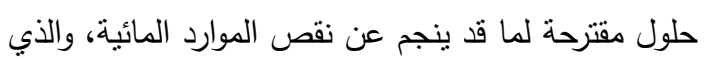
ينعكس سلبا على التتمية المستدامة. أهداف البحث: إستهدف البحث بصفة عامة رصد وتحليل الموقف البف الراهن لصادرات محصول القطن بإعتباره من أهم بإنة

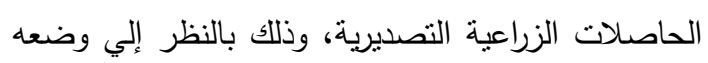

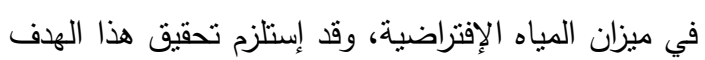

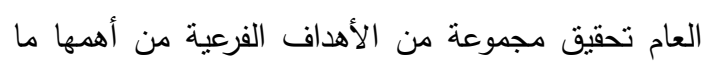
- تقدير كمية المياه الإفتراضية المصدرة لمحصول القطن. - تقدير العائد المزرعي والتصديري والمجتمعي لوحدة المياه المستخدمة في إنتاج المحصول. 
0.88 طـن/ فـدان عـامي 2012، 2013، وحـد أقصـي

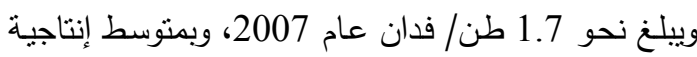

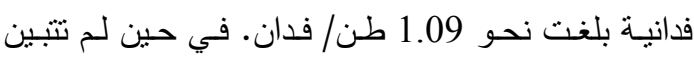

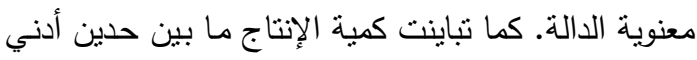

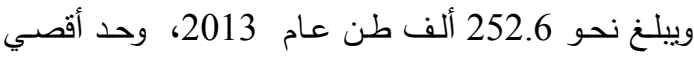
ويبلغ نحو 976.8 ألف طن عام 2007، وبمتوسط إنتاج بلغ نحو 561.4 ألف طن. وبمقدار نتاقص سنوي معنوي إحصائيا بلغ نحو 33.8 ألف طن، وبمعدل تغير بلغ نحو 6.02\% من متوسط الفترة، في حين نوضح قيهة معامل

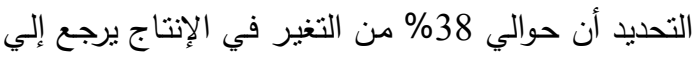

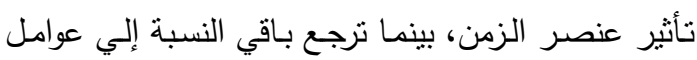

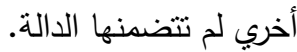

توضح بيانات ونتائج جداول (1، 2) نطور كل من مساحة وإنتاجية وإنتاج وكميـة وقيمة صـادرات محصدول

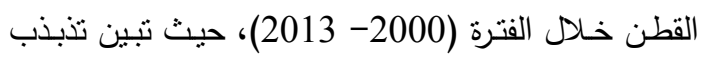
المساحة المنزرعة من المحصول ما بين حدين أدني ويبلغ

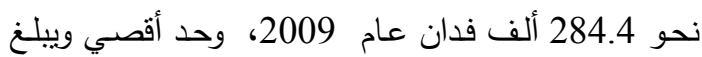
نحو 731.1 ألف فدان عـام 2001، وبمتوسط مسـاحة

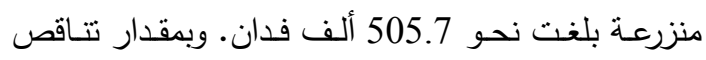
سنوي معنوي إحصائيا بلغ نحو 29.4 ألف فدان، وبمعدل تغير بلغ نحو 5.81\% من منوسط الفترة، في حين توضح

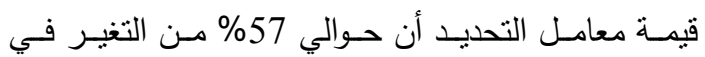

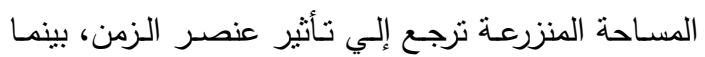

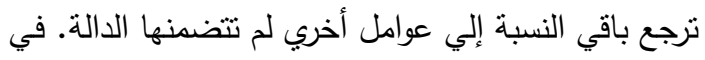

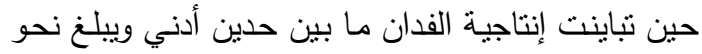

جدول (1): تطور المؤشرات الإتتاجية والتصديرية لمحصول القطن في مصر خلال الفترة (2000- 2013).

\begin{tabular}{|c|c|c|c|c|c|}
\hline قيمة الصادر جنيه & كمية الصنادرات & ألف طن الإنتاج & طن/ الإنتاجية & ألف فدانة & البيان \\
\hline 672.90 & 93.000 & 549.42 & 1.06 & 518.32 & 2000 \\
\hline 740.75 & 81.600 & 826.14 & 1.13 & 731.10 & 2001 \\
\hline 1490.23 & 161.11 & 755.81 & 1.07 & 706.36 & 2002 \\
\hline 2185.99 & 196.80 & 588.60 & 1.10 & 535.09 & 2003 \\
\hline 2992.42 & 183.90 & 779.06 & 1.09 & 714.73 & 2004 \\
\hline 1041.10 & 96.900 & 636.88 & 0.97 & 656.58 & 2005 \\
\hline 761.330 & 55.100 & 595.40 & 1.11 & 536.40 & 2006 \\
\hline 861.940 & 68.400 & 976.75 & 1.70 & 574.56 & 2007 \\
\hline 1055.14 & 90.600 & 315.83 & 1.01 & 312.70 & 2008 \\
\hline 485.480 & 39.020 & 278.74 & 0.98 & 284.43 & 2009 \\
\hline 785.210 & 42.900 & 376.52 & 1.02 & 369.14 & 2010 \\
\hline 1576.40 & 61.217 & 634.55 & 1.22 & 520.12 & 2011 \\
\hline 1186.40 & 85.545 & 293.69 & 0.88 & 333.36 & 2012 \\
\hline 931.730 & 43.405 & 252.60 & 0.88 & 286.72 & 2013 \\
\hline 1197.64 & 92.820 & 561.40 & 1.09 & 505.69 & المتوسط \\
\hline
\end{tabular}

المصدر: جمعت وحسبت من: وزارة الزراعة واستصلاح الأراضى، الإدارة المركزية للاقتصاد الزراعى، نشرة الإحصاءات الزراعية، ونشرة إحصاءات التجارة الخارجية لأهم السلع الزراعية، أعداد 
جدول (2): معادلات الإتجاه الزمني العام لتطور المؤثرات الإنتاجية والتصديرية لمحصول القطن في مصر خلال الفترة

(2013-2000)

\begin{tabular}{|c|c|c|c|c|c|}
\hline 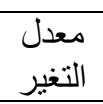 & 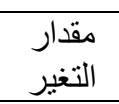 & $\mathrm{R}^{2}$ & $\mathrm{~F}$ & المعادلـــــــــــــة & البيان \\
\hline 5.81 & 29.38- & 0.57 & 4.9 & $\begin{array}{r}\hat{Y}=726.1-29.38 x \\
(-3.96)\end{array}$ & المساحة \\
\hline 6.02 & 33.79- & 0.38 & 7.38 & $\begin{array}{r}\hat{Y}=814.86-33.79 x \\
(-2.72)\end{array}$ & الإنتاج \\
\hline 22.88 & $21.2-$ & 0.60 & 4.9 & $\begin{array}{c}\hat{Y}=33.8+66.17 x-11.34 x^{2}+0.49 x^{3} \\
(2.21)^{*}(-2.48)^{*} \quad(2.43)^{*}\end{array}$ & كمية الصادر ات \\
\hline 19.53 & 233.9- & 0.34 & 1.73 & $\begin{array}{ccc}\hat{Y}=-301.9+1057.01 x-164.7 x^{2}+6.99 x^{3} \\
(2.1)^{*} \quad(-2.2)^{*} & (2.1)^{*}\end{array}$ & قيمة الصنادر ات \\
\hline
\end{tabular}

معدل التغير السنوي = (مقدار التغير ٪ متوسط الفترة) × 100.

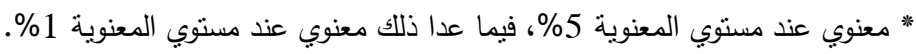

المصدر : جمعت وحسبت من بيانات جدول (1).

- العوامل المؤثرة علي إنتاج وتصدير القطن المصري

يتأثر إنتاج القطن المصري (y) مبالعديد من العوامل،

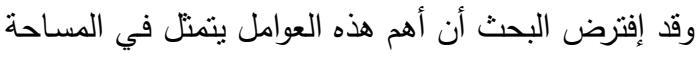

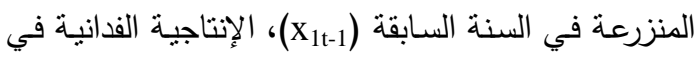
السنة السابقة (xt-1)، تكلفة إنتاج الفدان في السنة السابقة

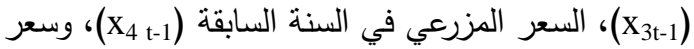

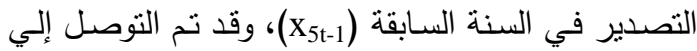

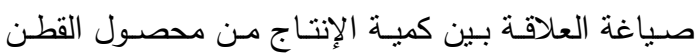
كمتغير تابع، وأهم هذه العوامل التفسيرية التي بعتقد تأثثرها علي هذا المتغير التابع خـال الفترة (2000- 2013) $\hat{\mathrm{Y}}=914.698-0.223 \mathrm{x}_{3 \mathrm{t}-1}+0.081 \mathrm{x}_{4 \mathrm{t}-1}$

$$
\text { علي النحو التالي: - مذي }
$$$$
(-3.7)
$$

$\mathrm{R}^{2}=0.63 \quad \mathrm{~F}=8.33$

ومن نتائج المعادلة يتبين أن هناك علاقة عكسية بين إجمالي الإنتاج المحلي من القطن و تكلفة إنتاج الفدان في السنة السابقة، حيث ينخفض إجمالي إنتاج الدحصول

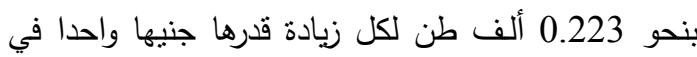
تكلفة إنتاج الفدان في السنة السابقة، في حين تبين أن هناك علاقة طردية بين إجمالي كمية الإنتاج وبين السعر

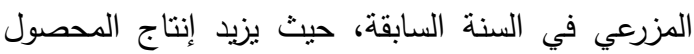

وتعد الصـادرات الزراعية من محصول القطن إحدي المصادر الضرورية لتوفير النقد الأجنبي لتمويل عمليات النتمية الثناملة، ومن هذا المنطلق يتضح من جدولي (1)

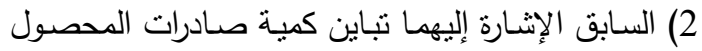
خلال هذه الفترة ما بين حدين أدني وبيلغ نحو 39.02 ألف طن عام 2009، وحد أقصي وييلـغ نحو 196.8 ألف طن عام 2003، وبمنوسط كمية صادرات بلغت نحو 92.82 ألف طن. وبمقدار نتاقص سنوي معنوي إحصائيا بلغ نحو 21.2 ألف طن، وبمعدل تغير بلغ نحو 22.9 من منوسط الفترة، في حين توضح قيمة معامل التحديد أن حوالي 60\% من التغير في كميـة الصسادرات ترجع إلي في تأثثر عنصر الزمن، بينما ترجع باقي النسبة إلي عوامل

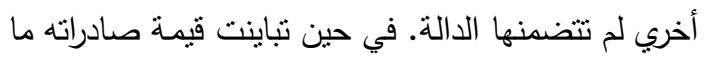

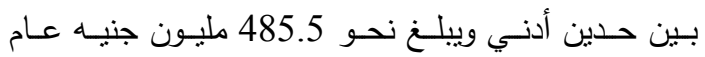
2009، وحد أقصسي ويبلغ نحو 2.99 مليـار جنيها عام 2004، وبمتوسط قيمـة صـادرات بلغت نحو 1.2 مليـار جنيـه. وبمقدار نتـاقص سنوي معنوي إحصـائيا بلـغ نحو

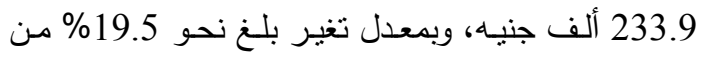

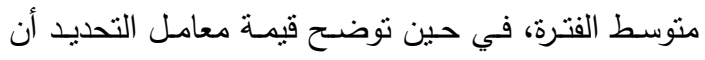
حوالي 34\% من التغير في قيمـة الصسادرات ترجع إلـي تأثثير عنصر الزمن، بينما ترجع باقي النسبة إلي عوامل

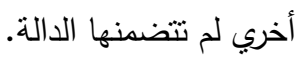


بلغت نحو 87.1 ألف فدان. وفيما يتعلق بالكقنن المائي

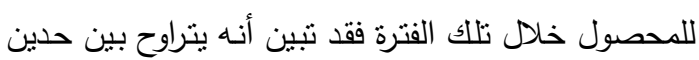

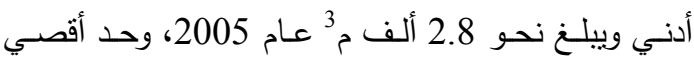
وييلغ نحو 3.9 ألف م³ عام 2013، بمتوسط مقنن مائي

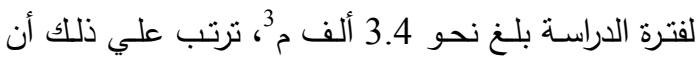

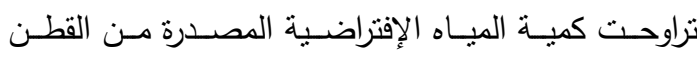

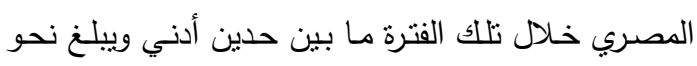

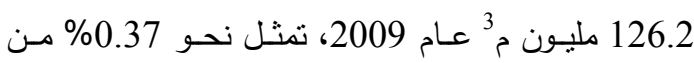

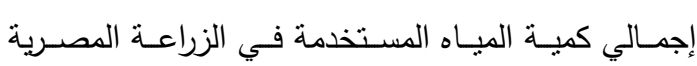

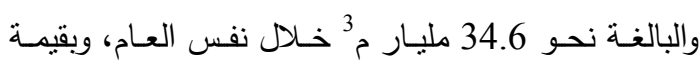

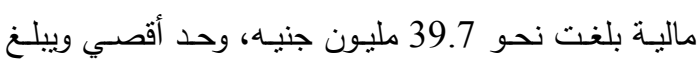

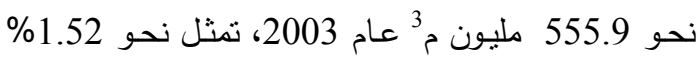
من إجمالي كمية المياه المستخدمة في الزراعة المصرية

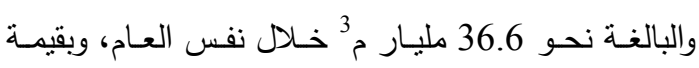

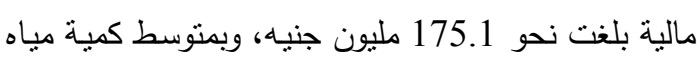

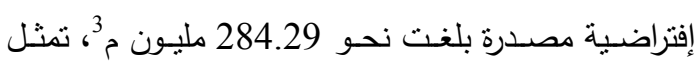

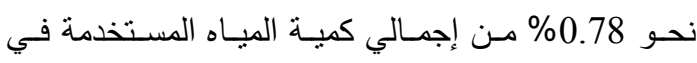

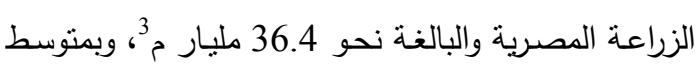
قيمة مالية بلغت 89.6 مليون جنيه خلال نفس الفترة.

\section{- العائد المزرعي والتصديري والمجتمعي لوحدة} المياه الإفتراضية المصدرة

توضـح بيانات ونتائج جداول (4، 5، 6) نطور العائد المزرعي والتصديري والمجتمي لوحدة المياه الإفتراضية المصدرة لمحصول القطن خلال الفترة (2000- 2013)، وقد تبين منه:

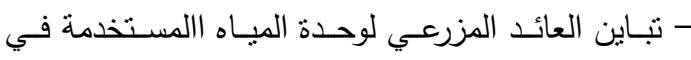
العملية الإنتاجية لمحصول القطن خلال الفترة المذكورة

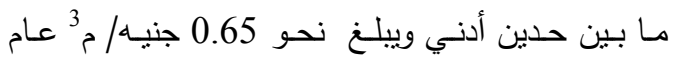
2000، تمثل نحو 43.8\% من منوسط العائد المزرعي لوني

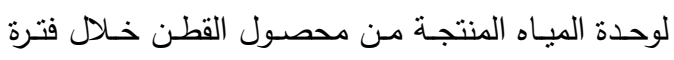

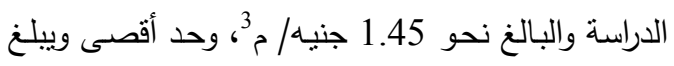
نحو 2.51 جنيه/ م عام 2010، يمثل
بنحو 0.081 ألف طن لكل زيادة قدرها جنيها واحدا في

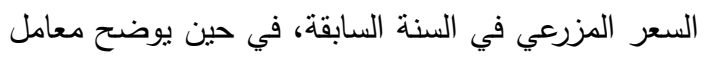
التحديد أن حوالي 63\% من التغيرات في كمية الإنتاج

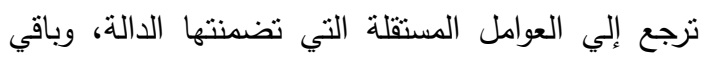
النسبة برجع إلي عوامل أخري غير مقيسة بالدالة.

كما تتأثر كمية صادرات القطن المصري (y) بالعديد

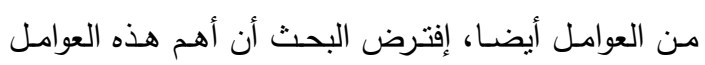

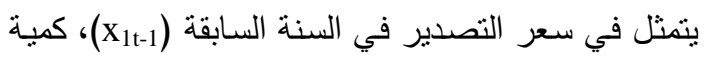

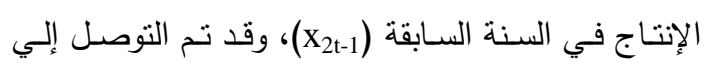

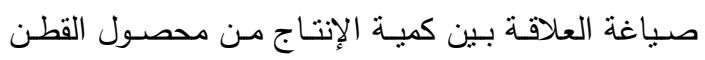
كمتغير تابع، وأهم هذه العوامل التفسيرية التي بعتقد تأثثرها علي هذا المتغير التابع خـال الفترة (2000- 2013) $\hat{\mathrm{Y}}=46.795-0.003 \mathrm{x}_{1 \mathrm{t}-1}+0.138 \mathrm{x}_{2 \mathrm{t}-1}$ علي النحو التالي: هذا:

$\mathrm{R}^{2}=0.40$

$$
\begin{array}{rr}
(-0.94) & (2.28) \\
F & =3.27
\end{array}
$$

ومسن نتـائج المعادلـة يتبـين أن هنـاك علاقـة طرديـة ومعنوية إحصائيا بين إجمالي كمية الصادرات من القطن المصري و بين كمية الإنتاج في السنة السابقة، حيث تزيد الهيد

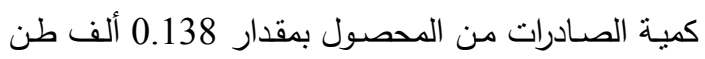
لكل زيادة قدرها ألف طن من الإنتاج المحلي في السنة السنة

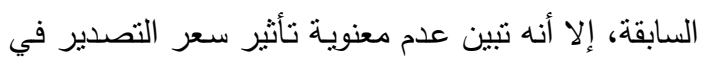

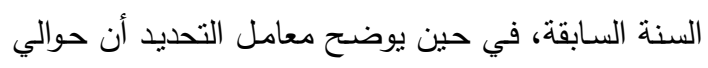

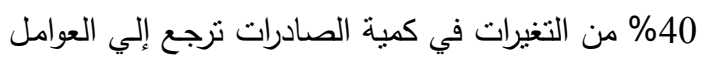
المستقلة التي تضمنتها الدالـة، وبـاقي النسبة يرجـع إلـي الصي عوامل أخري غير مقيسة بالدالة.

- تطور المساحة التصديرية وكمية وقيمة المياه الإفتراضية المصدرة

يتضــح مـن بيانـات جـدول (3) تطــور المســاحة

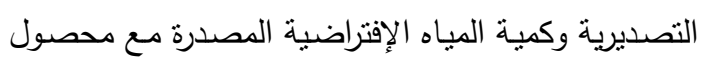

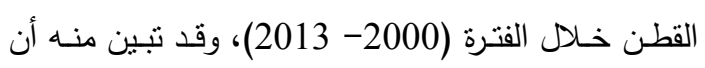
المساحه التصديرية قد تذبذبت بين حدين أدني وييلغ نحو 39.82 ألف فدان عام 2009 ، وحد أقصي ويبلـغ نحو 178.9 ألف فدان عام 2003، وبمتوسط مساحة تصديرية 
جدول (3): تطور المساحة التصديرية وكمية وقيمة المياه الإفتراضية لمحصول القطن في مصر خلال الفترة (2000-

.(2013

\begin{tabular}{|c|c|c|c|c|c|c|}
\hline \multirow{2}{*}{ 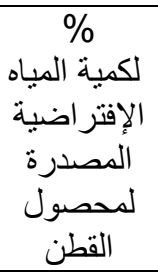 } & \multirow{2}{*}{ المياه المستخدية كمية } & \multicolumn{2}{|c|}{ كمية وقيمة المياه الإفتر اضية } & \multicolumn{2}{|c|}{ المساحة التصديرية } & \multirow{2}{*}{ البيان } \\
\hline & & ألف جنيهةرة** أليمة & ألفية الميدرة & اللمحقن المائي & ألف فديرية & \\
\hline 0.927 & 34.678 & 101294 & 321567 & 3665 & 87.74 & 2000 \\
\hline 0.688 & 34.757 & 75313 & 239087 & 3311 & 72.21 & 2001 \\
\hline 1.259 & 35.373 & 140277 & 445324 & 2957 & 150.6 & 2002 \\
\hline 1.521 & 36.552 & 175090 & 555842 & 3107 & 178.9 & 2003 \\
\hline 1.383 & 37.855 & 164895 & 523476 & 3103 & 168.7 & 2004 \\
\hline 0.946 & 29.800 & 88804 & 281918 & 2822 & 99.90 & 2005 \\
\hline 0.412 & 40.900 & 53039 & 168379 & 3392 & 49.64 & 2006 \\
\hline 0.334 & 42.100 & 44289 & 140599 & 3494 & 40.24 & 2007 \\
\hline 0.690 & 43.800 & 95221 & 302289 & 3370 & 89.70 & 2008 \\
\hline 0.365 & 34.600 & 39737 & 126150 & 3168 & 39.82 & 2009 \\
\hline 0.386 & 37.800 & 45934 & 145822 & 3467 & 42.06 & 2010 \\
\hline 0.580 & 30.870 & 56446 & 179193 & 3571 & 50.18 & 2011 \\
\hline 1.080 & 32.110 & 109224 & 346744 & 3571 & 97.10 & 2012 \\
\hline 0.539 & 37.820 & 64161 & 203685 & 3914 & 52.04 & 2013 \\
\hline 0.780 & 36.358 & 89552 & 284291 & 3350.9 & 87.06 & المتوسط \\
\hline
\end{tabular}

* المساحة التصديرية= كمية صادرات المحصول ٪ الإنتاجية الفدانية.

** كمية المياه الإفتراضية المصدرة= المساحة التصديرية × المقنن المائي للمحصول. *** قيمة المياه الإفتراضية المصدرة = كمية المياه الإفتراضية المصدرة × سعر المتر المكعب للمياه (31.5 قرش)(5، 6). المصدر: الجهاز المركزي للتعبئة العامة والإحصاء، نشرة إحصاءات الري، أعداد مختلفة، مرجع (5، 6).

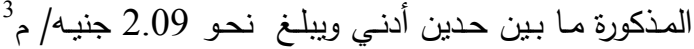
عـام 2000، تمثنـل نحـو 47.5\% مـن متوسـط العائـد التصديري لوحدة المياه الإفتراضية المصدرة من محصول

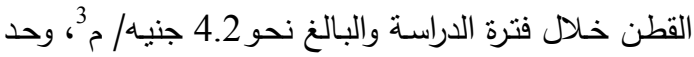
أقصى ويبلغ نحو 8.8 جنيـ/ م عام 2011، يمثل نحو 200\% مـن متوســ العائـد الإقتصـادي لوحــدة الميـاه الإفتراضـية المصــرة مسن محصــول القطـن خــلال فتـرة الدراسـة، وبـإنحراف معيـاري عـن المتوســـ قـدر بنحـو 1.7 \%ي حين تبين عدم معنوية الدالة.
نحـو 169.9\% مـن متوسـط العائدـ المزرعـي لوحـدة المياه المستخدمة في العملية الإنتاجيـة لمحصـول القطن خلال فتزة الدراسة، وتبين نزايد العائد المزرعي لوحدة المياه بمقـدار سـنوي معنـوي إحصـائيا بلـنغ نحسو 0.67 جنيـه، وبمعدل تغير بلغ نحو 7.2\%، كما يوضـح معامل التحديد أن نحو 54\% مـن التغيرات الحادثة في العائد المزرعي لوحدة المياه إنما يرجع لعامل الزمن، وبـاقي النسبة ترجع إلي عوامل أخري غير مقيسة بالدالة.

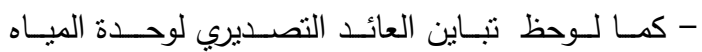
الإفتراضـية المصـدرة مـن محصــول القطن خـلال الفترة 


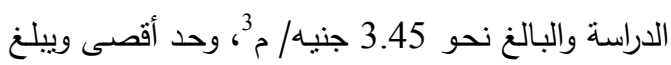

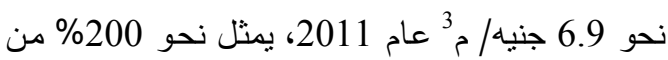

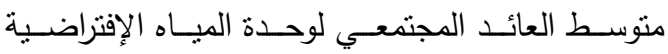

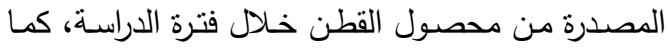
تبين عدم معنوية الدالة.
- كما لوحظ أيضـا من بيانـات جدول (6) تباين العائد

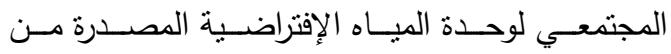
محصول القطن خلال الفترة المذكورة ما بين حدين أدني

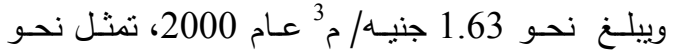
47.5 مـن متوسط العائد الهنمعي لوحدة الميـاه

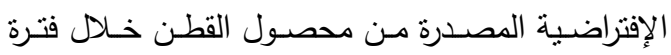

جدول (4): تطور العائد المزرعي والتصديري لوحدة المياه المستخدة في إنتاج وتصدير محصول القطن في مصر خلال الفترة (2000- 2013).

\begin{tabular}{|c|c|c|c|c|c|c|}
\hline لوحدة المياه جنيه/ & كمية المياه & قليمة الصادرات جنيه & لوحدة المياه العزئد المزيد & إيراد مزرعي فدان & المقنن المائي & البيان \\
\hline 2.093 & 321567 & 672.90 & 0.648 & 2373.7 & 3665 & 2000 \\
\hline 3.098 & 239087 & 740.75 & 0.764 & 2531.2 & 3311 & 2001 \\
\hline 3.346 & 445324 & 1490.23 & 0.950 & 2808.5 & 2957 & 2002 \\
\hline 3.933 & 555842 & 2185.99 & 1.212 & 3766.4 & 3107 & 2003 \\
\hline 5.716 & 523476 & 2992.42 & 1.381 & 4286.6 & 3103 & 2004 \\
\hline 3.693 & 281918 & 1041.10 & 1.616 & 4559.3 & 2822 & 2005 \\
\hline 4.522 & 168379 & 761.330 & 1.633 & 5538.0 & 3392 & 2006 \\
\hline 6.130 & 140599 & 861.940 & 1.317 & 4603.1 & 3494 & 2007 \\
\hline 3.491 & 302289 & 1055.14 & 1.252 & 4218.8 & 3370 & 2008 \\
\hline 3.848 & 126150 & 485.480 & 0.705 & 2234.1 & 3168 & 2009 \\
\hline 5.385 & 145822 & 785.210 & 2.508 & 8696.6 & 3467 & 2010 \\
\hline 8.797 & 179193 & 1576.40 & 2.311 & 8250.8 & 3571 & 2011 \\
\hline 3.422 & 346744 & 1186.40 & 1.830 & 6534.7 & 3571 & 2012 \\
\hline 4.574 & 203685 & 931.730 & 2.113 & 8269.1 & 3914 & 2013 \\
\hline 4.213 & 284291 & 1197.64 & 1.446 & 4905.1 & 3350.9 & المتوسط \\
\hline
\end{tabular}

* العائد المزرعي لوحدة المياه= إيراد الفدان المزرعي ٪ المقنن المائي. * العائد التصديري لوحدة المياه= قيمة صادرات المحصول ماليا ؛ كمية المياه الإفتراضية المصدرة. المصدر :جمعت وحسبت من بيانات جداول (1، 3، 7) بالدراسة.

جدول (5): معادلات الإتجاه الزمني العام لتطور العائد المزرعي لوحدة المياه لمحصول القطن في مصر خلال الفترة

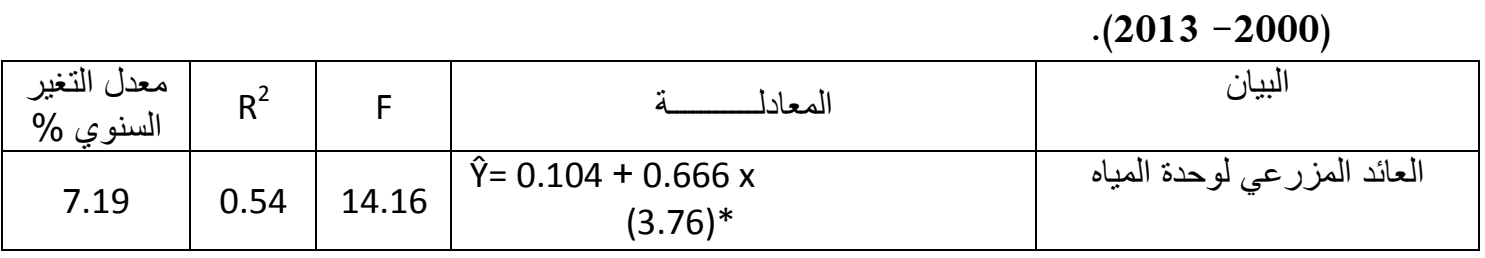

المصدر: جمعت وحسبت من بيانات جدول (4) بالدراسة. 


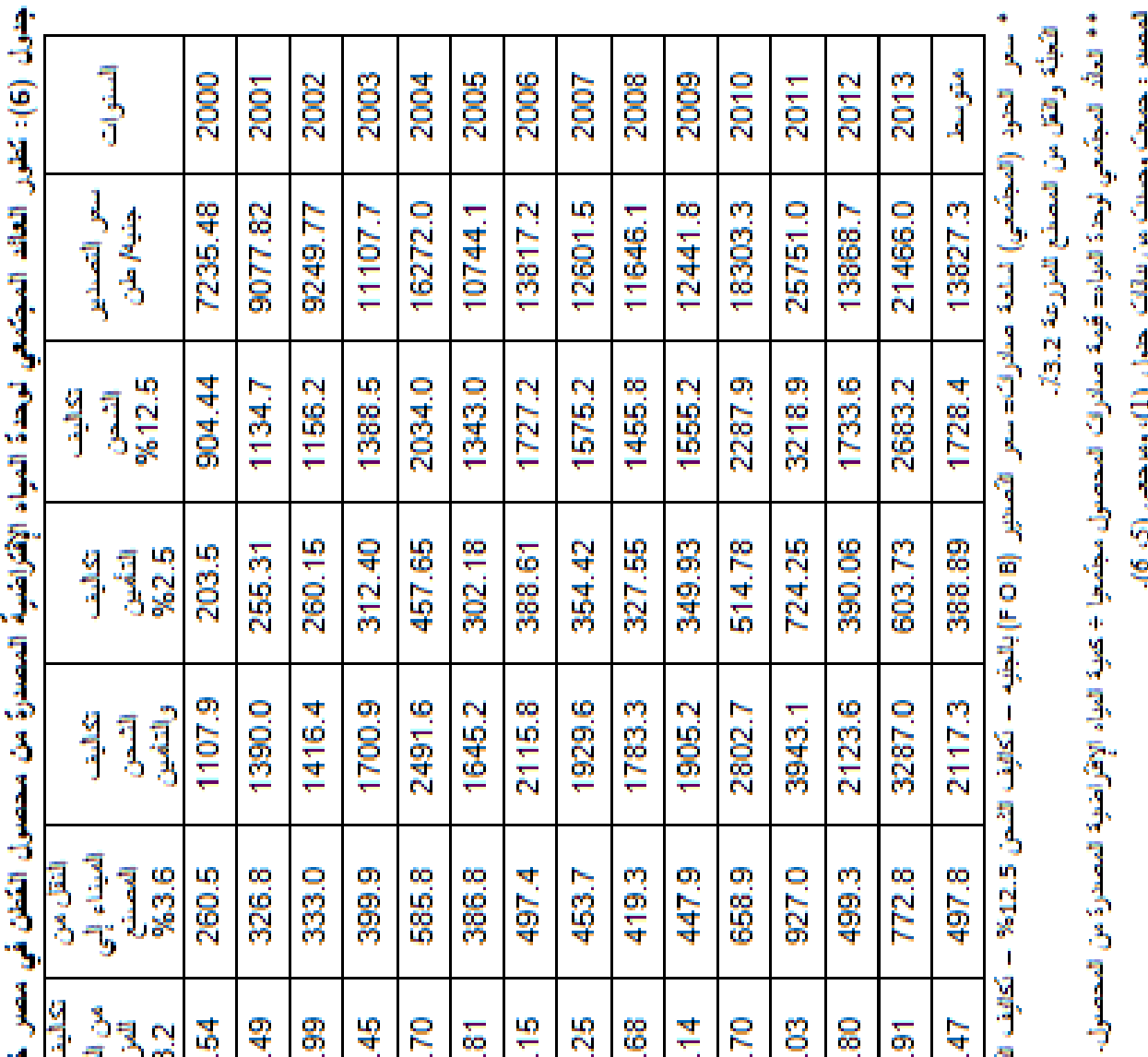

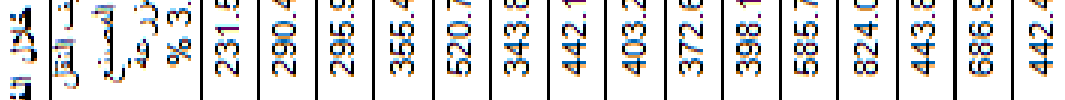

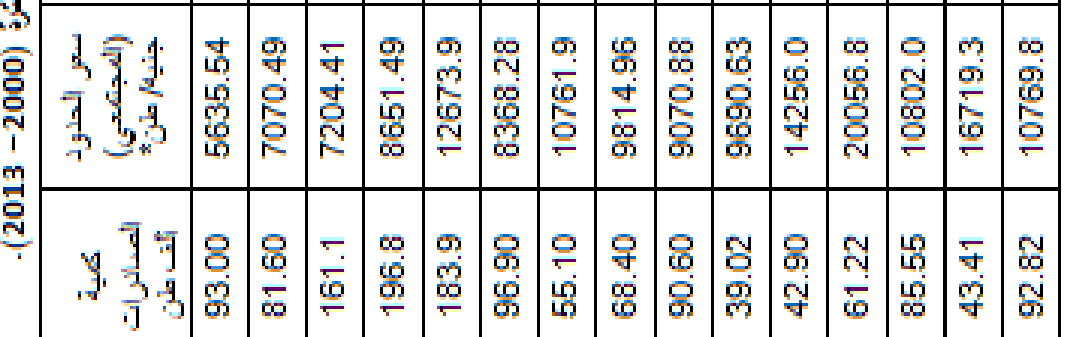

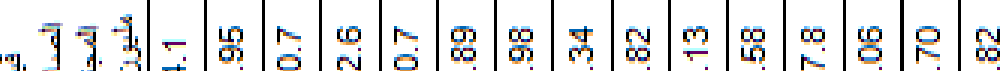

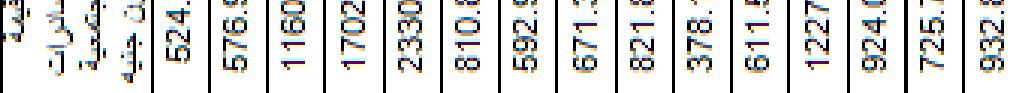

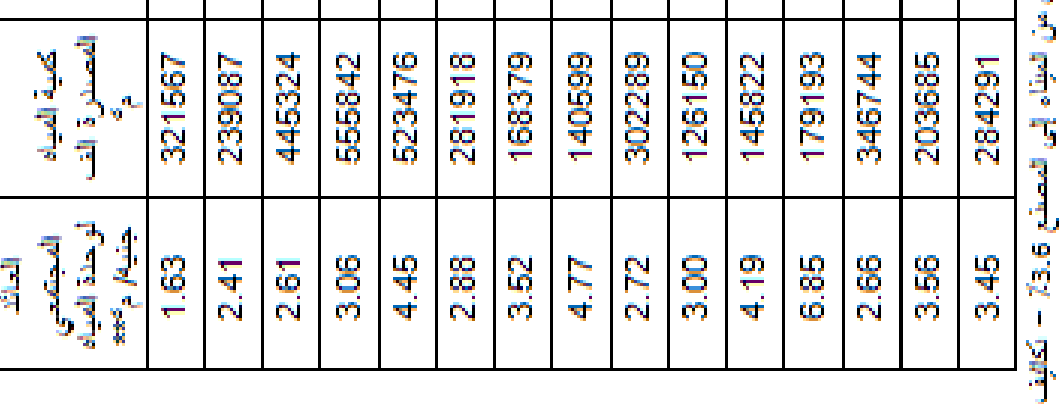


2013، تمثنل نحو 162.1\% مـن منوسط الفترة، وقد تباينت قيمة التكاليف الإنتاجية الفدانية بعد إضافة قيمة

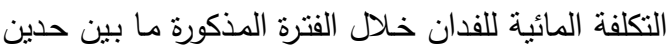
أدني وييلغ نحو 2994.5 جنيهاً عام 2002، يمثل نحو

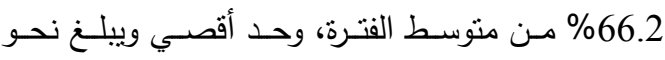

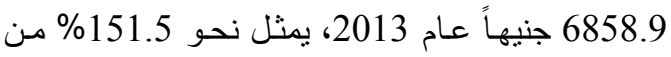
متوسط الفترة والبالغ نحو 4526.1 جنيهاً.

- بينما بلغ منوسط قيمة التكاليف المجتمعية الفدانية قبل

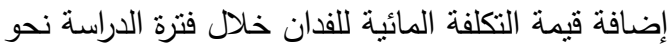

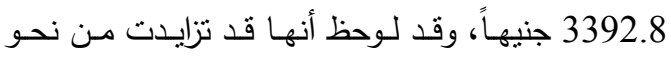

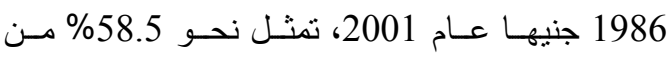
متوسط الفنزة، إلي نحو 5636 جنيهاً عام 2012، تمثل نحـ 166.1\% مـن متوسـط الفترة، وقد تباينـت قيمـة

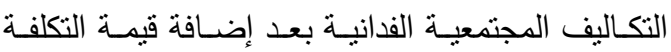
المائية للفدان خلال الفترة المذكورة ما بين حدين أدني

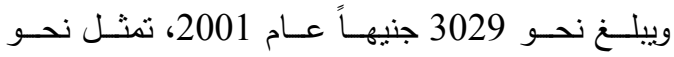

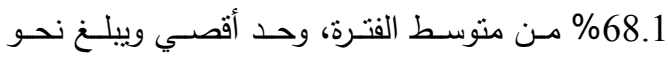
6760.9 جنيهاً عـام 2012، تمثنل نحو 152\% مسن وهن متوسط الفترة بمتوسط فترة بلغت نحو 4448.3 جنيهاً.

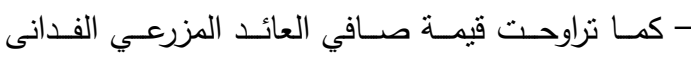
لمحصول القطن بعد خصـم قيمـة تكلفة الميـاه خـلال

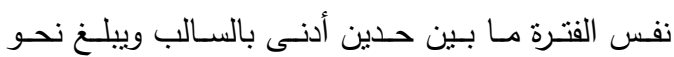

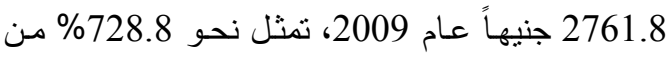
متوسط الفترة، وحد أقصي ويبلغ نحو 3033.5 جنيهاً عام 2011، تمثل نحو 6688.1\% من منوسط الفترة والبالغ نحو 378.97جنيهاً. بينما نزاوحت متوسط قيمة صافي العائد الفدانى التصديري لمحصول القطن بعد

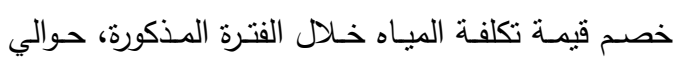
10561جنيهاً، وقد نباينت قيمة صافي العائد التصديري الفداني للمحصول بعد خصم قيمـة تكلفة المياه مـا بين حد أدني ويبلغ نحو 4517.6 جنيها عام 2000، تمثل نحو 42.8\% من منوسط الفترة، وحد أقصي وييلغ نحو 25346 جنيهاً عام 2011. تمثل
- الإحتياجات والتكلفة المائية وصافي العائد في ضوء الندرة النسبية للموارد المائية نظرا لعدم كفاية المعروض منها للوفاء بإحتياجات الطلب عليها، وبإعتبار

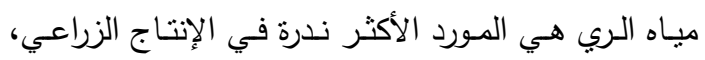

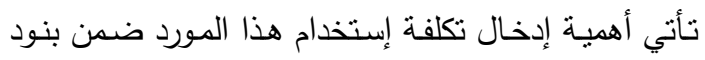
تكاليف الإنتاج، حيث أنـهـ مورد ذو قيمـة وعائد وتكلفـة فرصة بديلة، ومن ثم ضرورة الأخذ بعين الإعتبار إدراجه

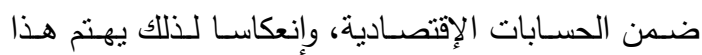

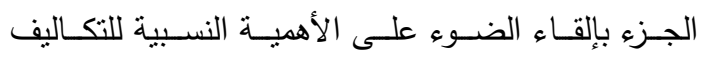
الإنتاجية الكلية مقومة بالأسعار المجتمعية حيث تم تحويل

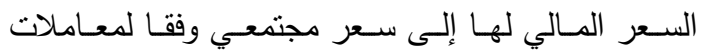
التحويل المطبقة من قبل البنك الدولي، منسوبة إلى العائد

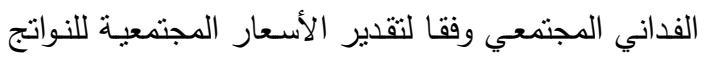

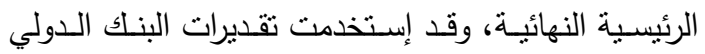
المدنلـة في تحويل تكلفة العمل البشـري (0.67)، العمل العل

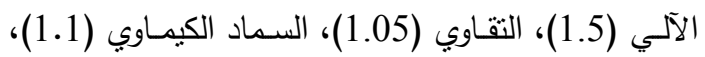

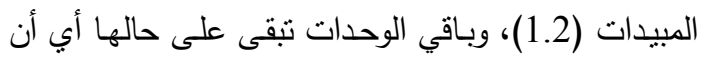

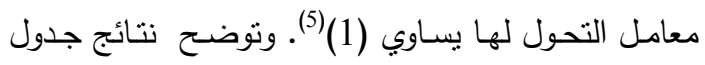
(7) نطور صـافي العائد الفداني بعد خصم نكلفة المياه

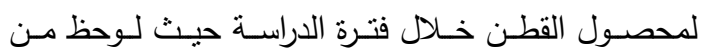

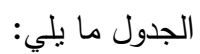

- تذبذبت قيمـة التكلفة المائيـة الفدانيـة لمحصـول القطن

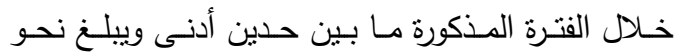
888.9 جنيـهـ عـام 2005، تمثـل نحـو 84.2\% مـن منوسط الفترة، وحد أقصي ويبلغ نحو 1232 جنيه عام

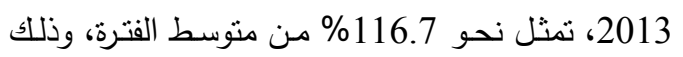

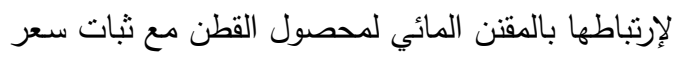

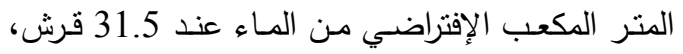
وبمتوسط فترة بلغت نحو 1055.5 جنيه. - في حين بلغ متوسط قيمة التكاليف الإنتاجية المزرعية الفدانبة قبل إضافة قيمة التكلفة المائية للفدان خلال فترة الدراسة نحو 3470.6 جنيهاً، وقد لوحظ أنها قد تزايدت فئل

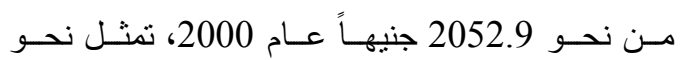
59.2 من منوسط الفترة، إلي نحو 5626 جنيهاً عام 


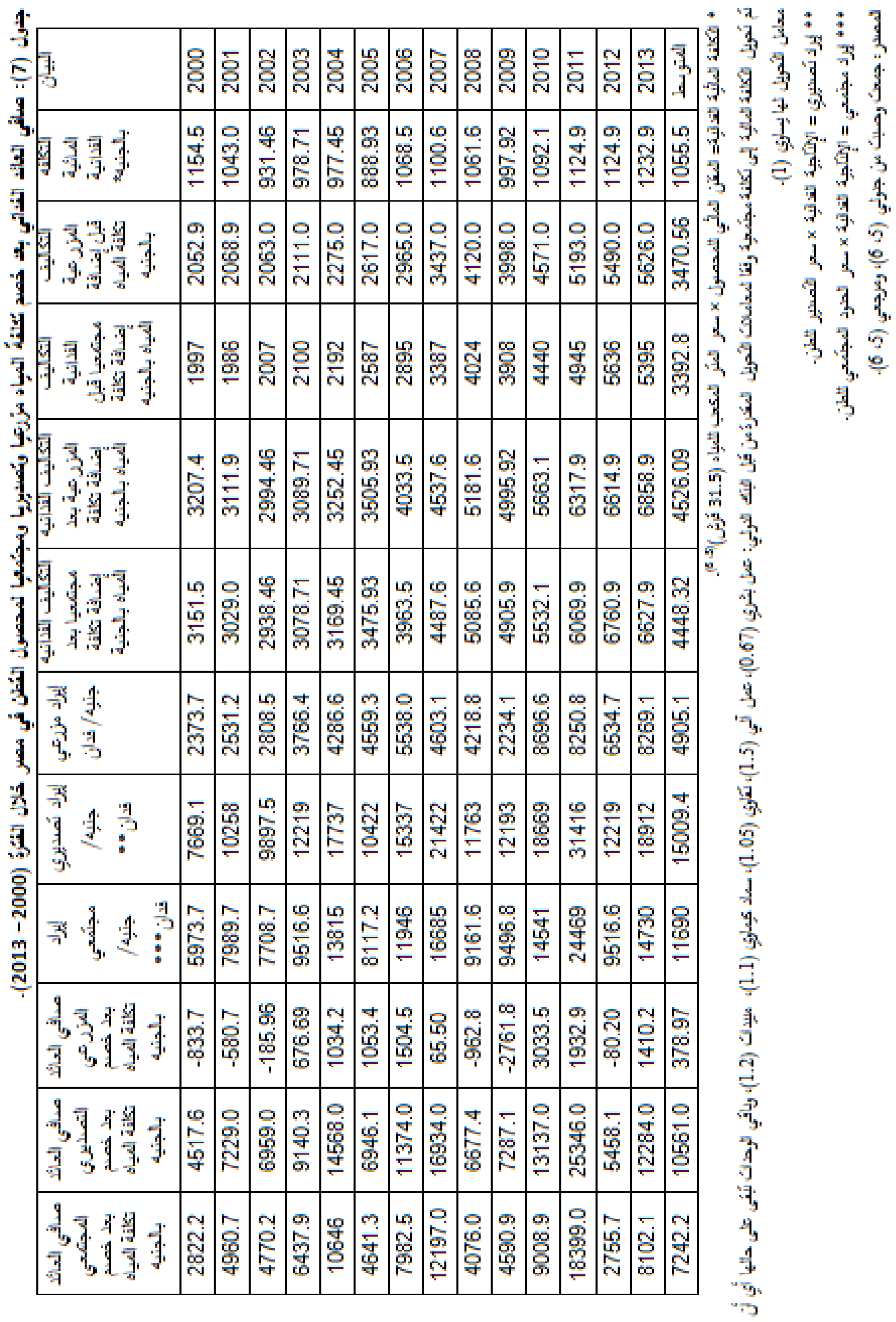


من منوسط الفترة والبالغ نحو 30.6 مليون جنيه. بينما بلغت منوسط قيمة صـافي العائد التصديري لإجمالي المساحة النصديرية لمحصول القطن بعد خصم قيمـة لفئة تكلفة المياه خلال الفترة الدذكورة، حوالي 848.7 مليون

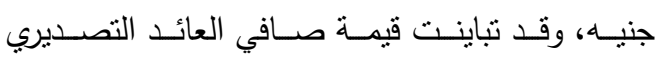
للمحصول للمساحة التصديرية بعد خصم قيمـة تكلفة المياه ما بين حد أدني ويبلغ نحو 396.4 مليون جنيه عام 2000، تمثنل نحو 46.7\% مـن منوسط الفترة،

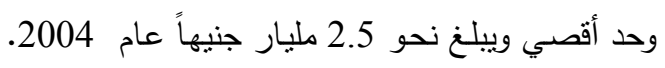
تمثل نحو 289.6\% من منوسط الفترة، بينما نزاوحت

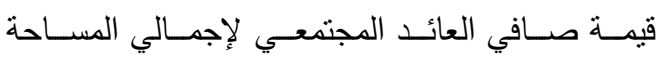

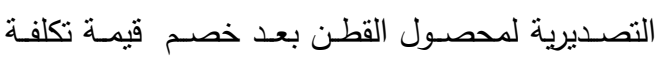
المياه خلال نفس الفترة ما بين حدين أدنى ويبلغ نحو

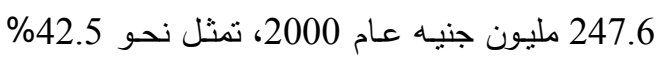
من منوسط الفترة، وحد أقصي وييلغ نحو 1.8 مليار

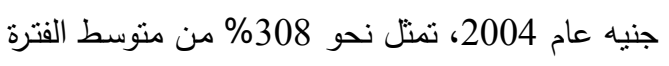
والبالغ نحو 583 مليون جنيه.

وبالتنالي يتبين ممـا سبق أنسه علي الرغم من حساب تكلفـة ميـاه الـري ضــن التكـاليف المزرعيـة والمجتمعيـة للفدان من محصول القطن، إلا أنـه يتحقق صـافي عائد موجب وبالرغم من إنخفاضه علي مستوي المزارع وإرتفاعه

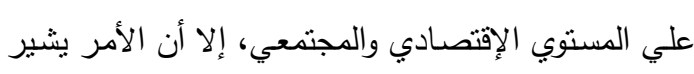

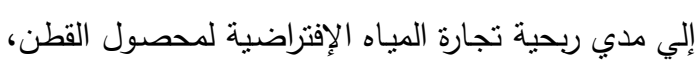

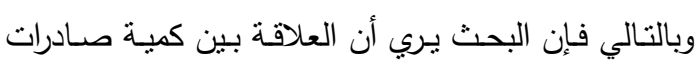

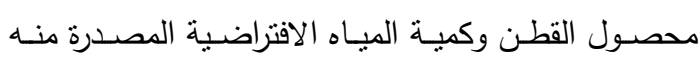

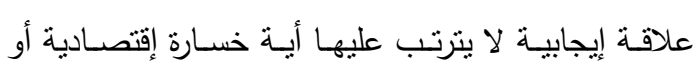

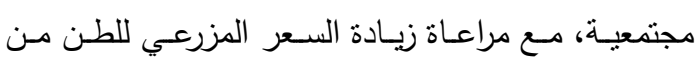
المحصول لرفع صافي العائد الذي يحصل عليه المزارع.
نحو 240\% من منوسط الفترة، بينما تراوحت قيمة صافي العائد المجتمعي الفدانى لمحصول القطن بعد خصم قيمة فئمة تكلفة المياه خلال نفس الفترة ما بين حدين أدنى وييلغ نحو بعد

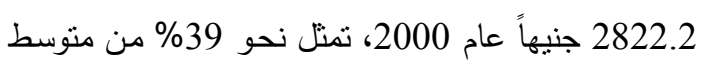

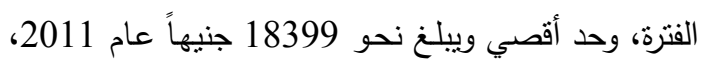
تمثل نحـو 254.1\% مـن متوسـط الفتـرة والبـالغ نحـو

7242.2

\section{- التكلفة المائية وصافي العائد التصديري}

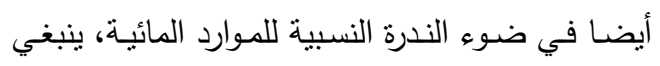
ضرورة الأخذ بعين الإعتبار إدراج حسابات نكلفة المياه الإفتراضية علي المسنوي القومي ضمن ما عرف بالمساحة الإنة

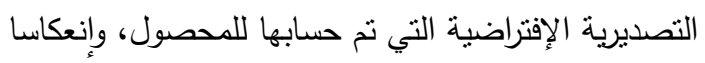

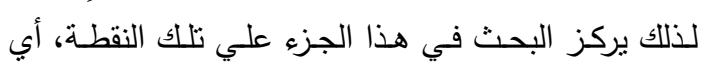

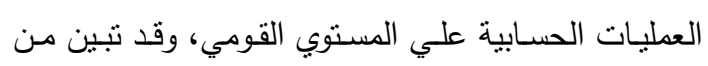
جدول (8) ما يلي: العملية - تذبـذبت قيمـة التكلفة المائيـة الكلية لإجمالي المسـاحة

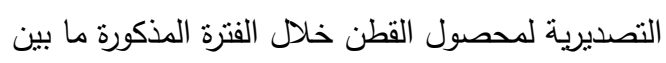
حدين أدنى وييلغ نحو 39.7 مليون جنيه عام 2009، تمثل نحو 44.3\% مـن منوسط الفترة، وحد أقصـي

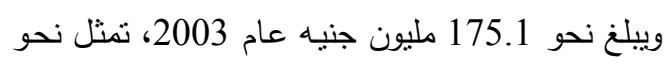
195.4 من منوسط الفترة، وذلك لإرتباطها بالمساحة

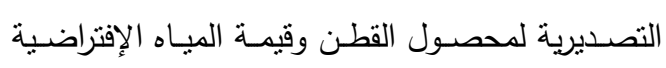
الفدانية، بمنوسط فترة بلغت نحو 89.6 مليون جنيه. - كما تراوح إجمالي قيمة صافي العائد المزرعي للمساحة

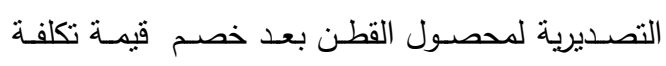

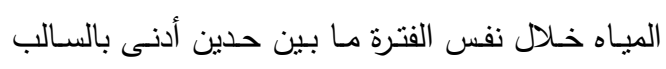

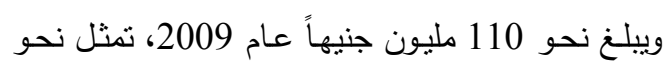
359.5 من منوسط الفترة، وحد أقصي ويبلغ نحو 174.5

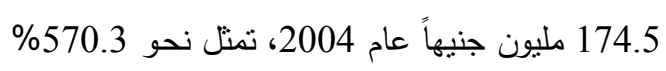


جدول (8): صـافي العائـد الفداني بعد خصم تكلفة الميـاه مزرعيا وتصديريا ومجتمعيا لإجمـالي المسـاحة التصديرية لمحصول القطن في مصر خلال الفترة (2000- 2013).

\begin{tabular}{|c|c|c|c|c|c|}
\hline 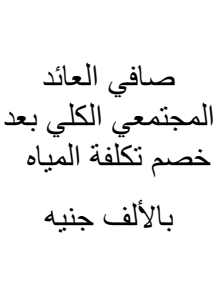 & بلتصديري الكلئي & خصم تكلية الكلي بعد & التكلفة المائية الكلية & ألف فداحة التصديرية & البيان \\
\hline 247619.8 & 396374.2 & -73148.8 & 101296 & 87.74 & 2000 \\
\hline 358212.1 & 522006.1 & -41932.3 & 75315 & 72.21 & 2001 \\
\hline 718392.1 & 1048025 & -28005.6 & 140278 & 150.6 & 2002 \\
\hline 1151740 & 1635200 & 121059.8 & 175091 & 178.9 & 2003 \\
\hline 1795980 & 2457622 & 174469.5 & 164896 & 168.7 & 2004 \\
\hline 463665.9 & 693915.4 & 105234.7 & 88804.1 & 99.90 & 2005 \\
\hline 396251.3 & 564605.4 & 74683.38 & 53040.3 & 49.64 & 2006 \\
\hline 490807.3 & 681424.2 & 2635.72 & 44288.1 & 40.24 & 2007 \\
\hline 365617.2 & 598962.8 & -86363.2 & 95225.5 & 89.70 & 2008 \\
\hline 182809.6 & 290172.3 & -109975 & 39737.2 & 39.82 & 2009 \\
\hline 378914.3 & 552542.2 & 127589 & 45933.7 & 42.06 & 2010 \\
\hline 923261.8 & 1271862 & 96992.92 & 56447.5 & 50.18 & 2011 \\
\hline 267578.5 & 529981.5 & -7787.42 & 109228 & 97.10 & 2012 \\
\hline 421633.3 & 639259.4 & 73386.81 & 64160.1 & 52.04 & 2013 \\
\hline 583034.6 & 848710.9 & 30631.4 & 89552.9 & 87.06 & المتوسط \\
\hline
\end{tabular}

- التكلفة المائية الكلية= المساحة التصديرية × التكلفة المائية الفدانية. - صافي العائد المزرعي الكلي بعد خصم تكلفة المياه= المساحة التصديرية × صافي العائية المائدة المزرعي الفداني بعد خصم تكلفة المياه.

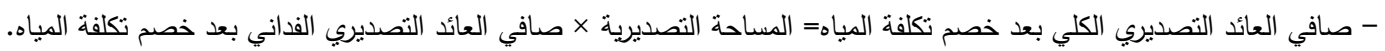
- صافي العائد المجتمعي الكلي بعد خصم تكلفة المياه= المساحة التصديرية ×صافي العائد المجتمعي الفداني بعد خصم تكلفة المياه. المصدر: جمعت وحسبت من بيانات جدولي (1، 7).

دكتوراه، قسم الإقتصاد الزراعي، كلية الزراعة، جامعة

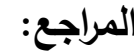

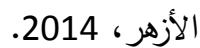
(1) أحمد سعد محمد راثند، دراسة تحليلية للوضع الحالي

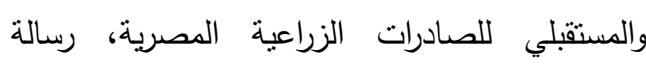


هاني سعيد عبد الرحمن الثتلة (دكتور)، تقدير

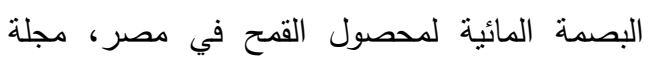
المجلس العربي للمياه، الماء، المجلد السادس، العدد لئد الأول، يونيو 2015.

(7) هاني سعيد عبد الرحمن الثتلة (دكتور)، محددات فاقد المياه وكفاءة نقل وتوصيل الموارد المائية النيلية في مصر ، مجلة المجلس العربي للمياه، الماء، المجلد السادس، العدد الأول، يونيو 2015.

(8) غادة عبد الفتاح مصطفي (دكتور)، دراسة إقتصادية لإنتاج وتصدير القطن المصري، المجلة المصرية

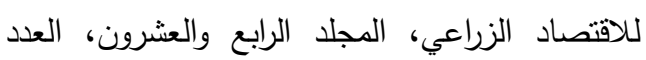

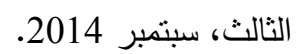

(9) الجهاز المركزي للتعبئة العامة والإحصاء، النشرة

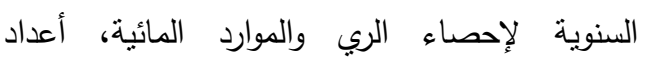

$$
\text { (2013-2000) }
$$

(10) وزارة الزراعة واستصلاح الأراضى، الإدارة المركزية للاقتصاد الزراعى، نشرة الإحصاءات الزراعية، أعداد الاداعها

$$
\text { .2000) }
$$

(2) محفوظ حامد الطوخي (دكتور)، وآخرون، دراسة (6) (1أنة

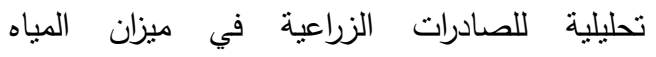

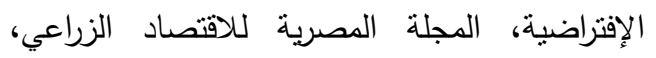

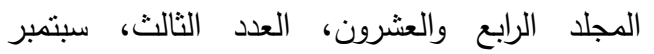
.2014

(3) محمد نعمان نوفل (دكتور)، نطور التكلفة المائية للصادرات الزراعية خلال الفترة (2000- 2007)، نوفيل المجلة المصرية للاقتصاد الزراعي، المجلد التاسع عشر ، العدد الثالث، سبتمبر 2009. (4) هاني سعيد عبد الرحمن الثتلة (دكتور)، هالة محمد الثند

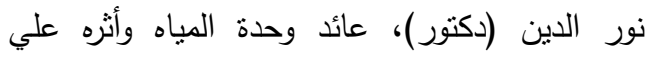

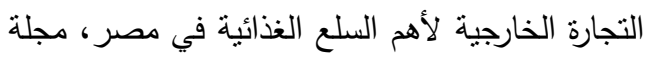

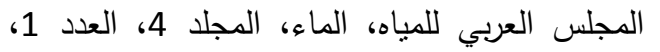
(5) هاني سعيد عبد الرحمن الثنلة (دكتور)، وآخرون،

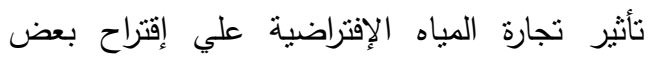

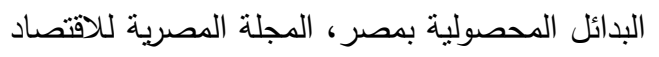

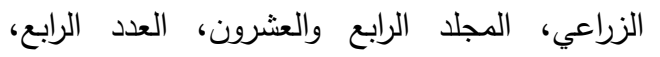
ديسمبر 2014. - (2014. 


\title{
FOREIGN TRADE EXPORTS COTTON CROP AND RELATIONSHIP VIRTUAL WATER
}

\author{
H. M. Sediek \\ The higher Institute of agricultural co-operation
}

\begin{abstract}
Water is one of the most important problems which is generally affecting the economic development and particularly affecting agriculture development. It is being one of the most important determinants of developments in different areas. Therefore there is a need to adopt a strategy for food security which involves water policy.

The research depends on the published secondary data from various sources has been adopted, as well as numerous research and studies related to the search topic. Find the stylistic descriptive and quantitative statistical analysis, which are commensurate with the data was based.
\end{abstract}

\section{The results of the study show that:}

As For the development of the export area, quantity and value of virtual water exports shows that the area of exports has ranged from a minimum of about 39.82 thousand acres in 2009, and a maximum of about 178.9 thousand acres in 2003. With regards to actual water of the crop during that time it has been shown that it ranged between a minimum of about 2.8 thousand $m 3$ in 2005, and a maximum of about 3.9 thousand in 2013, which resulted to the fact that the amount of virtual water exported from Egyptian cotton during that period ranged from a minimum of about 126.2 million $\mathrm{m} 3$ in 2009, representing approximately $0.37 \%$ of the Total amount of water used in agriculture in Egypt which was about 34.6 billion $\mathrm{m} 3$ during the same year at a value of about 39.7 million pounds, and a maximum of about 555.9 million $\mathrm{m3}$ in 2003, representing approximately $1.52 \%$ of the total water used in agriculture in Egypt amounting to about 36.6 billion $\mathrm{m} 3$ during the same year at a value of about 140.3 million pounds, with an average amount of exported virtual water of about 284.29 million m3 which represents $0.78 \%$ of the total water used in agriculture in Egypt that was 36.4 billion m3 during the same period.

As For the farm yield, export yield and social yield for a unit of virtual water exported the study has shown the variation of farm yield per virtual water exported used in the production process of cotton crop between a minimum of about 0.65 pounds / $m 3$ in 2000, and a maximum of about 2.51 pounds $/ \mathrm{m} 3$ in 2010. The variation of export yield per virtual water exported used in the production process of cotton crop between a minimum of about 2.09 pounds / $m 3$ in 2000, and a maximum of about 8.8 pounds / $\mathrm{m} 3$ in 2011 while the function has shown to be insignificant. The variation of social yield per virtual water exported used in the production process of cotton crop ranged between a minimum of about 1.63 pounds $/ \mathrm{m} 3$ in 2000, and a maximum of about 6.9 pounds/ $m 3$ in 2011 while the function has shown to be insignificant.

As for the cost of water and the net return the study has shown the variation of the water cost per acre of cotton crops between a minimum of about 888.9 pounds in 2005, and a maximum of about 1232 pounds in 2013. While the average production costs totaled before adding the water cost per acre value to about 2052.9 pounds in 2000, and a maximum of about 5626 pounds in 2013, also the average production costs value after the addition of water cost per acre varies within a minimum of about 2994.5 pounds in 2002, and a maximum of about 6858.9 pounds in 2013. While the value of social costs before adding water cost per acre of about 1986 pounds in 2001 to about 5636 pounds in 2012. The value of net yield per acre of cotton crop ranged after deducting the value of the cost of water from a minimum of about $-2,761.8$ pounds in 2010, to a maximum of 25,346 pounds in 2011. while the average value of net return per acre of cotton crop exports after deducting the value of the cost of water is about 10561 pounds, also the value of social net return per acre after deducting the value of water cost ranges between 2822.2 pounds in 2000 and 18399 pounds in 2011.

On the other hand, the value of water cost of total exported cotton ranged between a minimum of 39.7 million pounds in 2003 and a maximum of 175.1 million pounds in 2009 . The total value of farm net return for exported cotton crop area after deducting the value of water cost ranges 


\section{Sediek}

from a minimum of -110 million pounds in 2009 and a maximum of 174.5 million pounds in 2004, while the average export net return value for total cotton crop exported area after deducting the value of water cost was 848.7 million pounds. The value of net returns for exported cotton crop after deducting the value of water costs ranges from a minimum of 396.4 million pounds in 2000 and a maximum of 2.5 billion pounds in 2004. The value of social net returns for exported cotton crop area after deducting the value of water costs ranges from a minimum of 247.6 million pounds in 2000 and a maximum of 1.8 billion pounds in 2004 .

And thus can be seen from the foregoing that in spite of the water expense a net positive return is achieved indicating how profitable virtual water trade is for cotton crop. The research shows that the relationship between the quantity of cotton exports and the quantity of virtual water exported is a positive relationship that does not cause any economic or social loss. In light of the previous results the research recommends the following:

- Increasing the cultivated area of cotton.

- Increasing farm price received by farmers from the cotton.

- Increasing the export capacity of the cotton.

- The need of introducing water resource value within the cost and benefit analysis while making economic decisions related to production and export policy for cotton crop and considering water resource an economic resource that is tradable and mobile. Also water is a resource that can be exchanged both locally and internationally, this exchange is through calculating the price of water, and the opportunity cost which is based on the consumer 's price to get the true value of water consumed.

Key words: Foreign trade- cotton- virtual water 